Check for updates

Cite this: RSC Adv., 2017, 7, 34104

Received 5th May 2017

Accepted 30th June 2017

DOI: $10.1039 / c 7 r a 05090 a$

rsc.li/rsc-advances

\section{Porous carbon with large surface area derived from a metal-organic framework as a lithium-ion battery anode material $\dagger$}

\author{
Hai-Jun Peng, ${ }^{a}$ Gui-Xia Hao, ${ }^{b}$ Zhao-Hua Chu, ${ }^{b}$ Yin-Wan Lin, ${ }^{a}$ Xiao-Ming Lin (DD *ac \\ and Yue-Peng Cai ${ }^{\star a}$
}

A new Cd-based metal-organic framework (Cd-MOF), namely $\left[\mathrm{Cd}_{3}(\mathrm{TCPB})_{2}\left(\mathrm{H}_{2} \mathrm{O}\right)_{2}(\mathrm{DMF})_{2}\right] \cdot 7 \mathrm{H}_{2} \mathrm{O}$, has been constructed from $\mathrm{Cd}\left(\mathrm{NO}_{3}\right)_{2}$ and 1,3,5-tri(4-carboxyphenoxy)benzene $\left(\mathrm{H}_{3} \mathrm{TCPB}\right)$ under solvothermal conditions. Single crystal $\mathrm{X}$-ray diffraction analyses reveal that $\mathrm{Cd}$-MOF displays a two-dimensional $(3,6)$ connected kgd net topology based on linear trinuclear $\mathrm{Cd}_{3}(\mathrm{COO})_{6}$ secondary building units (SBUs) and exhibits one-dimensional opening channels. When treated as a precursor by calcining this $\mathrm{Cd}-\mathrm{MOF}$ at $800{ }^{\circ} \mathrm{C}$ for $2 \mathrm{~h}$, a porous carbon material was prepared. As an anode material for lithium-ion batteries (LIBs), the resulting porous carbon material exhibited an initial discharge of $2486 \mathrm{~mA} \mathrm{~h} \mathrm{~g}^{-1}$ and a charge of $1683 \mathrm{~mA} \mathrm{~h} \mathrm{~g}^{-1}$ at a current density of $300 \mathrm{~mA} \mathrm{~g}^{-1}$ with a high initial coulomb efficiency of $98 \%$. After 300 cycles, a high reversible capacity as high as $1285 \mathrm{~mA} \mathrm{~h} \mathrm{~g}^{-1}$ could be still maintained, along with good rate capability and superior cyclic stability. The good electrochemical performance can be attributed to the unique pore structure and large surface area, which can largely offer more active sites for Li storage and cause an increase in the ability for the accumulation of charges.

\section{Introduction}

With the increasing demand for high-energy density power batteries, lithium-ion batteries (LIBs) have gained sustained research and development in recent decades. ${ }^{1}$ There is more and more interest in developing anode materials with high specific capacity and excellent cycle reversibility for next generation high-energy density rechargeable LIBs. ${ }^{2}$ Due to their good safety, stability and large electrical conductivity, porous carbonaceous composites have recently been found to have great potential as electrode materials. However, traditional commercial graphite materials with a capacity of only $372 \mathrm{~mA} \mathrm{~h}$ $\mathrm{g}^{-1}$ cannot meet the demands of high-energy density power batteries. ${ }^{3}$ Therefore, it still remains a challenge to find highenergy density carbon materials.

Metal-organic frameworks (MOFs) with designable framework structures, tunable pore sizes and large surface area as

${ }^{a}$ Guangzhou Key Laboratory of Materials for Energy Conversion and Storage, School of Chemistry and Environment, South China Normal University, Guangzhou 510006, P. R. China.E-mail: linxm@scnu.edu.cn; caiyp@scnu.edu.cn

${ }^{b}$ College of Chemistry and Environmental Engineering, Hanshan Normal University, Chaozhou, Guangdong 521041, P. R. China

${ }^{c}$ Key Laboratory of Theoretical Chemistry of Environment, Ministry of Education, School of Chemistry and Environment, South China Normal University, Guangzhou 510006, P. R. China

$\dagger$ Electronic supplementary information (ESI) available: CCDC 1539624. For ESI and crystallographic data in CIF or other electronic format see DOI: 10.1039/c7ra05090a well as facile fabrication, are emerging as a new kind of crystalline functional material and have attracted great attention in many fields, such as energy-storage systems, ${ }^{4}$ catalysis, ${ }^{5}$ drug delivery, ${ }^{6}$ chemical sensors, ${ }^{7}$ etc. MOFs have been regarded as an effective precursors or templates to construct the corresponding porous carbon materials which could be applied in energy storage devices such as lithium/sodium ion batteries ${ }^{8-10}$ and supercapacitors. ${ }^{11-13}$ For example, Pan et al. prepared porous carbon polyhedra (PCP) by directly thermal treatment of zeolitic imidazolate framework-8 (ZIF-8) for supercapacitors, which exhibits a high specific capacitance of $275.69 \mathrm{~F} \mathrm{~g}^{-1} \cdot{ }^{14}$ In the latest report, Li et al. designed and synthesized a porous carbon through the vacuum pyrolysis of a Zn-based MOF at $1000{ }^{\circ} \mathrm{C}$. And a high capacity of $2458 \mathrm{~mA} \mathrm{~h} \mathrm{~g}^{-1}$ was obtained at $0.2 \mathrm{C}$. $^{15}$ Based on these aforementioned studies, carbon materials derived from MOF as templates are expected to possess excellent electrochemical performance than the traditional porous carbon materials.

We have been working on crystal engineering of porous frameworks and applied for energy storage. ${ }^{16-19}$ As reported in our previous work, a porous microtube carbon was obtained by using a cadmium-based MOF (Cd-MOF) as template through directly pyrolysis, when treated as an anode materials, it displayed an improved capacity of $741 \mathrm{~mA} \mathrm{~h}^{-1}$ and superior cyclic stability. ${ }^{20}$ As part of continuous work, herein, we synthesized a two dimensional (3,6)-connected framework with rutile topology, namely $\left[\mathrm{Cd}_{3}(\mathrm{TCPB})_{2}\left(\mathrm{H}_{2} \mathrm{O}\right)_{2}(\mathrm{DMF})_{2}\right] \cdot 7 \mathrm{H}_{2} \mathrm{O}\left(\mathrm{H}_{3} \mathrm{TCPB}=\right.$ 1,3,5-tri(4-carboxyphenoxy)benzene). Through direct pyrolysis 
of this MOF, a porous carbon material was created with improved cycling stability and excellent rate capability.

\section{Experimental section}

\section{Materials}

All the reagents and solvents employed were purchased from commercial sources and used without further purification. The organic ligands 1,3,5-tri(4-carboxyphenoxy)benzene $\left(\mathrm{H}_{3} \mathrm{TCPB}\right.$, Fig. 1a) was synthesized according to a reported method. ${ }^{21,22}$ Infrared spectra were collected from $\mathrm{KBr}$ pellets in the range of $4000-400 \mathrm{~cm}^{-1}$ on a Nicolet/Nexus-670 FT-IR spectrometer. The elemental analyses were recorded by a PerkinElmer 240 elemental analyzer. Raman spectra were obtained on a Renishaw inVia confocal Raman microscope equipped with an argon ion laser beam. Thermogravimetric analyses (TGA) were performed on a Netzsch Thermo Microbalance TG 209 F3 Tarsus from room temperature to $900{ }^{\circ} \mathrm{C}$ with a heating rate of $10{ }^{\circ} \mathrm{C} \mathrm{min}^{-1}$ under flowing nitrogen. The X-ray powder diffraction patterns were measured on a Bruker D8 Advance diffractometer at $40 \mathrm{kV}$ and $40 \mathrm{~mA}$ with a $\mathrm{Cu}$ target tube and a graphite monochromator. The sorption isotherms were measured at 77 $\mathrm{K}$ with a Quantachrome Autosorb-iQ2-MP gas sorption analyzer.
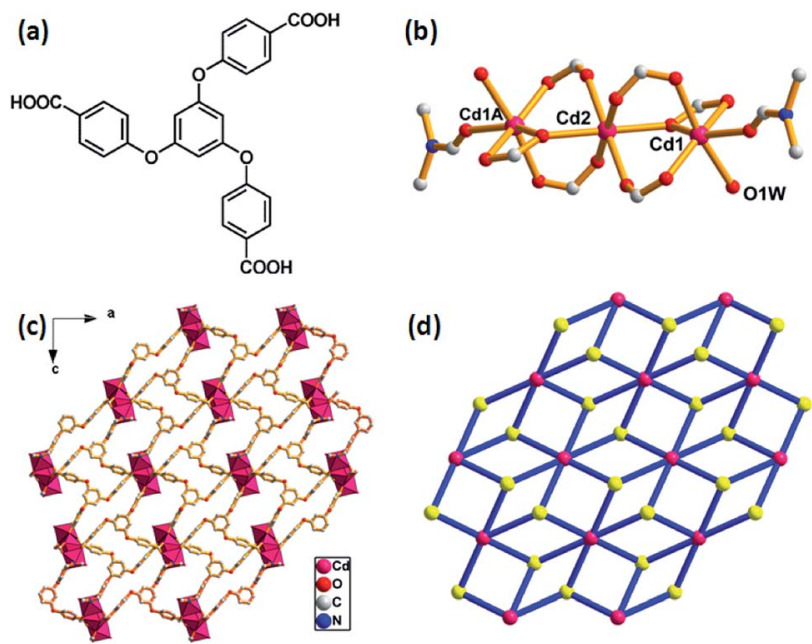

(e)

(f)
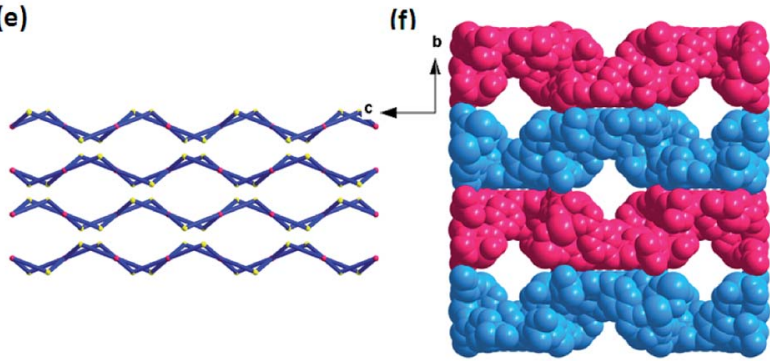

Fig. 1 Crystal structure of Cd-MOF. (a) 1,3,5-tri(4-carboxyphenoxy) benzene, $\left(\mathrm{H}_{3} \mathrm{TCPB}\right)$. (b) Linear trinuclear cadmium clusters as a SBU. Symmetry code: (A) $1-x, 1-y,-z$. (c) Polyhedral view of 2-D network along the $b$-axis. (d) View of the $(3,6)$-connected kgd net topology with the Schläfli symbol of $\left(4^{3}\right)_{2}\left(4^{6} \cdot 6^{6} \cdot 8^{3}\right)$. (e) Stacking of 2-D layers in an $A B A B$ modes along the $a$-axis. (f) A space-filling view of the network between the adjacent layers (blue and pink), showing 1-D channels along a-axis. $\mathrm{H}$ atoms are omitted for clarity.
Scanning electron microscopy (SEM, ZEISS Ultra 55, Germany) operating at $5 \mathrm{kV}$ was used to characterize the morphologies. Xray photoelectron spectroscopy (XPS) spectrum was recorded on an ESCA Lab250 XPS spectrometer using $\mathrm{Al} \mathrm{K} \alpha$ radiation.

\section{Preparation of $\left[\mathrm{Cd}_{3}(\mathrm{TCPB})_{2}\left(\mathrm{H}_{2} \mathrm{O}\right)_{2}(\mathrm{DMF})_{2}\right] \cdot 7 \mathrm{H}_{2} \mathrm{O}$}

A mixture of $\mathrm{Cd}\left(\mathrm{NO}_{3}\right)_{2} \cdot 4 \mathrm{H}_{2} \mathrm{O}(30 \mathrm{mg}, 0.1 \mathrm{mmol})$ and $\mathrm{H}_{3} \mathrm{TCPB}$ $\left(25 \mathrm{mg}, 0.05 \mathrm{mmol}\right.$ ) was dissolved in $6 \mathrm{~mL} \mathrm{DMF}$ and $1 \mathrm{~mL} \mathrm{H}_{2} \mathrm{O}$. The reaction mixture was sealed in a Teflon-lined autoclave and heated under autogenous pressure at $90{ }^{\circ} \mathrm{C}$ at a rate of $1{ }^{\circ} \mathrm{C}$ $\mathrm{min}^{-1}$ for three days. After cooling to room temperature at a rate of $0.1{ }^{\circ} \mathrm{C} \mathrm{min}^{-1}$, block-shaped colorless crystals were obtained and washed with DMF. Yield: $75 \%$ (based on the ligand). Anal. calcd for $\mathrm{C}_{60} \mathrm{H}_{62} \mathrm{~N}_{2} \mathrm{O}_{29} \mathrm{Cd}_{3}(\%)$ : C, 44.69; $\mathrm{H}, 3.88 ; \mathrm{N}, 1.74$. Found: C, 44.65; H, 3.86; N, 1.70. IR (KBr, $\left.\mathrm{cm}^{-1}\right): 3422(\mathrm{br}), 1655(\mathrm{~m})$, 1595(s), 1542(w), 1500(w), 1457(m), 1390(s), 1224(m), 1163(m), 1116(m), 1005(w), 868(w), 783(w).

\section{Electrochemical measurements}

The porous carbon was fabricated by calcining the as-prepared Cd-MOF under the nitrogen atmosphere at $800{ }^{\circ} \mathrm{C}$ for $2 \mathrm{~h}$. Then the resulting sample were washed by HF acid for 2 days, and dried under vacuum. The active carbon material, super $P$ carbon black conductive material, and polyvinylidene fluoride (PVDF) binder in a weight ratio of $7: 2: 1$ was stirred together with $N$ methylpyrrolidone (NMP) as a solvent. The slurry was coated on a $10 \mu \mathrm{m}$ copper foil current collector and dried at $70^{\circ} \mathrm{C}$ for $18 \mathrm{~h}$ in a vacuum over. Subsequently, circular disks of $12 \mathrm{~mm}$ in diameter were cut. After that, the cells were assembled in an argon-filled glove box with the moisture and oxygen content below $0.1 \mathrm{ppm}$. The electrochemical behavior of the activated $\mathrm{Pb}$-MOF material was performed using coin-type half cells $(2025$ type) with a Li counter electrode separated by a Celgard 2400 membrane as the separator. $1 \mathrm{M} \mathrm{LiPF}_{6}$ in diethyl carbonate (DEC) and ethylene carbonate (EC) $(1: 1$ volume) formed the electrolyte. The galvanostatic charge/discharge tests were performed between $0.01 \mathrm{~V}$ and $3.0 \mathrm{~V}$ by using the LAND CT2001A multichannel battery testing system at room temperature. And the cyclic voltammetry $(\mathrm{CV})$ measurements were measured on a CHI660C Electrochemical Workstation at a scan rate of $0.1 \mathrm{mV}$ $\mathrm{s}^{-1}$ in a potential range of $0.01-3.0 \mathrm{~V} v s$. $\mathrm{Li}^{-\mathrm{Li}^{+}}$.

\section{X-ray crystallographic studies}

Suitable single crystal was carefully selected under an optical microscope and glued to thin glass fiber. Structural measurement was collected on an Oxford Gemini S Ultra diffractometer equipped with $\mathrm{Cu}_{\mathrm{K} \alpha}$ radiation $(\lambda=1.54178 \AA)$ at $150 \mathrm{~K}$ by using $\phi$ and $\omega$ scan. ${ }^{23}$ The reflections have been corrected by empirical absorption corrections. The structures were solved by the direct method and refined by full-matrix least-squares on $F^{2}$ using SHELXL programs (SHELXTL-2014). ${ }^{24}$ All non-hydrogen atoms were located successfully from Fourier maps and refined by anisotropic thermal parameters. Because there are many highly disordered solvent molecules, their diffraction contribution was removed by using the PLATON/SQUEEZE. ${ }^{25}$ Structures were then refined again using the data generated. The guest molecules can be confirmed 
by the TGA and elemental analyses (C, H and N). Crystallographic data for the structure is provided in Table $\mathrm{S} 1 \dagger$ and the selected bond lengths and bond angles are listed in Table S2.†

\section{Results and discussion}

\section{Crystal structure of $\left[\mathrm{Cd}_{3}(\mathrm{TCPB})_{2}\left(\mathrm{H}_{2} \mathrm{O}\right)_{2}(\mathrm{DMF})_{2}\right] \cdot 7 \mathrm{H}_{2} \mathrm{O}$}

The as-prepared Cd-MOF crystal was determined and structurally characterized by single crystal X-ray diffraction analysis as the formula $\left[\mathrm{Cd}_{3}(\mathrm{TCPB})_{2}\left(\mathrm{H}_{2} \mathrm{O}\right)_{2}(\mathrm{DMF})_{2}\right] \cdot 7 \mathrm{H}_{2} \mathrm{O}$, which was further determined by TGA and EA. Structural analyses reveal that the Cd-MOF crystallizes in orthorhombic Fddd space group and the structure contains a linear trinuclear cadmium clusters at the crystallographic inversion centre with the $\mathrm{Cd} 1-\mathrm{Cd} 2$ distance of $2.756 \AA$ and the Cd1-Cd2-Cd1A bond angle of $180^{\circ}$. As shown in Fig. $1 \mathrm{~b}$, the centre $\mathrm{Cd}(2)$ ion exhibits an octahedral coordination surrounding by six oxygen atoms form six bridging carboxylate groups. The two terminal $\mathrm{Cd} 1$ and $\mathrm{Cd} 1 \mathrm{~A}$ ions reside in a distorted octahedral coordination spheres, defined by four oxygen atoms from three carboxylate groups and two oxygen atoms from ligated $\mathrm{H}_{2} \mathrm{O}$ and DMF molecules. The trinuclear cadmium clusters as secondary building units (SBUs) are united together by six ligands to generate a 2D layer structure (Fig. 2c). A better insight into the nature of this structure, the whole $2 \mathrm{D}$ sheet can be seen as a $(3,6)$-connected kgd network by simplifying the ligand as a 3connecting node and the trinuclear cadmium clusters as a 6connecting node (Fig. 2d). An appealing structural feature is that the $2 \mathrm{D}$ layers are stacked in an $\mathrm{ABAB}$ fashion without interpenetration (Fig. 1e), giving a 1D channel with the effective pore size of $8.7 \times 8.7 \AA^{2}$ (Fig. 1f). The solvent accessible volume is $3562 \AA^{3}$ per unit cell, and the pore volume ration is calculated to be $32 \%$ by the PLATON program.

\section{Characterization}

Field emission scanning electron microscopy (FESEM) was used to investigate the sizes and morphologies of the products. As
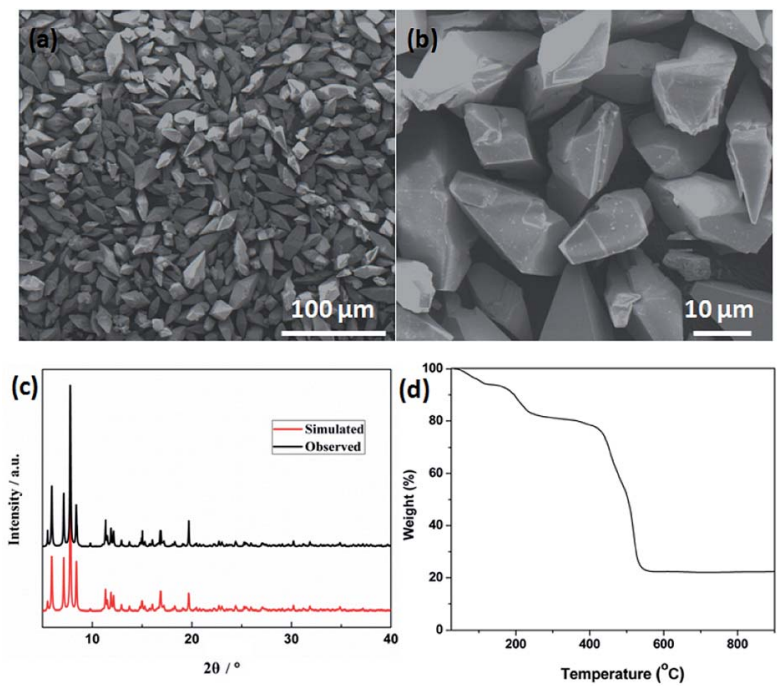

Fig. 2 (a) Low- and (b) high-magnified FESEM images. (c) XRD pattern. (d) TGA curve of the Cd-MOF precursor. seen in Fig. 2a, the as-prepared Cd-MOF particles are relatively uniform with length and width of about 20 and $10 \mu \mathrm{m}$, respectively. A magnified FESEM image in Fig. 2b reveals that the surfaces of the polyhedral shape microcrystal are relatively smooth from different view angles. Infrared spectrum (IR) analysis showed that the characteristic adsorption peaks around $3300 \mathrm{~cm}^{-1}$ corresponded to the $\nu(\mathrm{OH})$ vibrations of the water molecules (Fig. S1†). Strong peaks at 1669 and $1394 \mathrm{~cm}^{-1}$ were assigned to asymmetric and symmetric stretching vibrations for the carboxylate groups. The XRD pattern of the asmade Cd-MOF shows that all diffraction peaks match well with the simulated pattern results (Fig. 2c), indicating the high phase purity of the samples. Thermogravimetric analysis (TGA) was also employed to examine the thermal stability under an $\mathrm{N}_{2}$ atmosphere. As shown in Fig. 2d, TGA curve shows the first weight loss from temperature to $150{ }^{\circ} \mathrm{C}$ amounting to $7.86 \%$, which may be attributed to the loss of seven $\mathrm{H}_{2} \mathrm{O}$ guest molecules (calcd $7.82 \%$ ). Then the MOF undergoes a second weightloss step between $200{ }^{\circ} \mathrm{C}$ and $450{ }^{\circ} \mathrm{C}$, corresponding to the loss of two coordinated $\mathrm{H}_{2} \mathrm{O}$ and DMF molecules $(11.7 \%$ experimentally vs. $11.3 \%$ calculated). The framework suffers from serious weight loss upon heating to $450{ }^{\circ} \mathrm{C}$ due to the decomposition of the structure.

Based on the TGA analysis, the Cd-MOF could be decomposed into $\mathrm{CdO}$ and porous carbon at the temperature high than $550{ }^{\circ} \mathrm{C}$, similar decomposition behavior could be reported in the previous document. ${ }^{26}$ As a result, the Cd-MOF template was directly heated at $800{ }^{\circ} \mathrm{C}$ in nitrogen gas for $2 \mathrm{~h}$. Obviously, PXRD pattern in Fig. $\mathrm{S} 2 \uparrow$ demonstrated the formation of $\mathrm{CdO}$ and $\mathrm{C}$. Then the resulting samples were washed by $\mathrm{HF}$ acid to ensure the removal of the $\mathrm{CdO}$ composite and dried under vacuum to obtain the final product. As revealed in the FLSEM images in Fig. 3, the surface of products becomes very rough and is decorated with a number of holes, indicating the formation of pores during the calcination process. The PXRD pattern of the final product was shown in Fig. 4a. All the diffraction peaks can be assigned to the porous carbon (JCPDS no. 41-1487) with two broad peaks at $23^{\circ}$ and $43^{\circ}$, corresponding to the carbon (002) and (101) peak, respectively. The XRD pattern indicates that pure porous carbon was obtained without any Cd element. Energy-dispersive X-ray spectroscopy (EDS) indicates that the product mainly contains $\mathrm{C}$ and $\mathrm{O}$ elements (Fig. S3†). The absence of the other signal further confirmed that the Cd element had been removed completely. The presence of $\mathrm{O}$ peak probably originated from the oxygen adsorbed in the carbon material. ${ }^{27}$ Raman spectrum shows two broad peaks centered at around $1351 \mathrm{~cm}^{-1}$ (D-bond) and $1589 \mathrm{~cm}^{-1}$ (Gbond) are also detected simultaneously (Fig. 4b), corresponding to the disordered carbon and the ordered graphitic carbon, respectively. ${ }^{28}$ The intensity of $G$ peak is greatly enhanced than that of $D$ peak, suggesting a great increasing degree of graphitization of the carbon in the final samples. ${ }^{29} \mathrm{X}$-ray photoelectron spectroscopy (XPS) spectrum verifies the existence of $\mathrm{O}$ and $\mathrm{C}$ elements in the obtained carbon (Fig. 4c). The porosity of the carbon material was further characterized by $\mathrm{N}_{2}$ adsorptiondesorption isotherms. Fig. 4d indicates the presence of mesopore and macropores in the resultant materials with large 

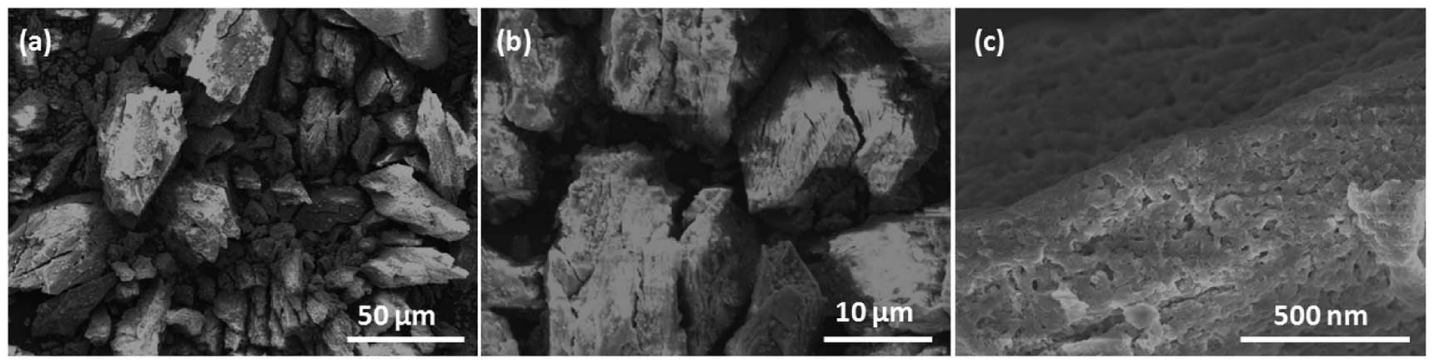

Fig. 3 FLSEM images at different magnifications of the obtained porous carbon.

hysteresis loops. The inset in Fig. 4d displays the results of a pore size analysis by applying Barrett-Joyner-Halenda (BJH) method. It is evident that the carbon material possesses two kinds of pore characteristics, including mesopores peaked at $\sim 46 \mathrm{~nm}$ and macropores centered at $\sim 52 \mathrm{~nm}$, respectively. The Brunauer-Emmett-Teller (BET) surface is $1796 \mathrm{~m}^{2} \mathrm{~g}^{-1}$ with a pore volume of $2.62 \mathrm{~cm}^{3} \mathrm{~g}^{-1}$. There are two advantages by using Cd-MOF as precursor: (i) Cd-MOF possess abundant carbon sources, which can be transferred into carbon material after pyrolysis. (ii) The morphology remains essentially unchanged and more holes and pores formed after heating treatment. Nitrogen adsorption-desorption isotherms of CdMOF in Fig. S4 $\dagger$ present the typical type I microporous behavior with the specific surface area of $348 \mathrm{~m}^{2} \mathrm{~g}^{-1}$. The formed carbon material shows the meso- and macro-porous structure. Such large surface provides a convenient and accessible route to electrolyte diffusion and intercalation of Li-ions, which is favorable for enhancing the electrochemical performances of the electrode.

\section{Electrochemical analysis as an anode material for LIBs}

The lithium-storage properties of the as-prepared porous carbon were investigated by using the standard half-cell configuration. Fig. 5a presents the first three consecutive cyclic voltammogram $(\mathrm{CV})$ curves of the electrode at a scan rate of $0.1 \mathrm{mV} \mathrm{s}^{-1}$ in the voltage range of $0.01-3 \mathrm{~V} v s$. Li. In the first cathodic cycle, an irreversible reduction peak at around $0.60 \mathrm{~V}$

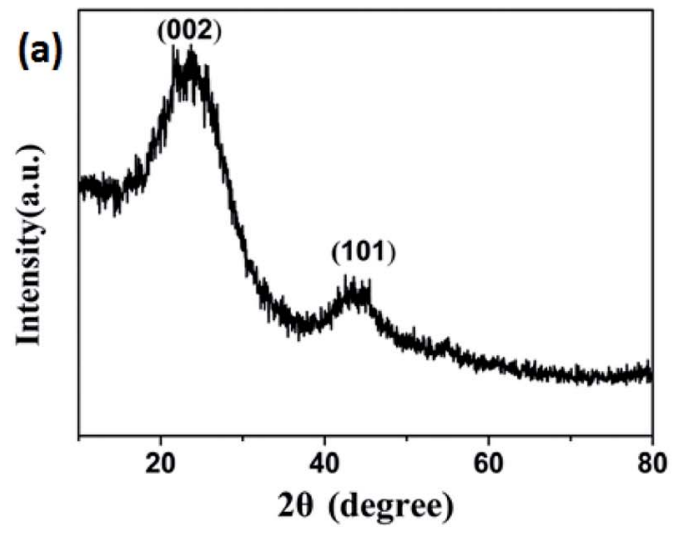

(b)
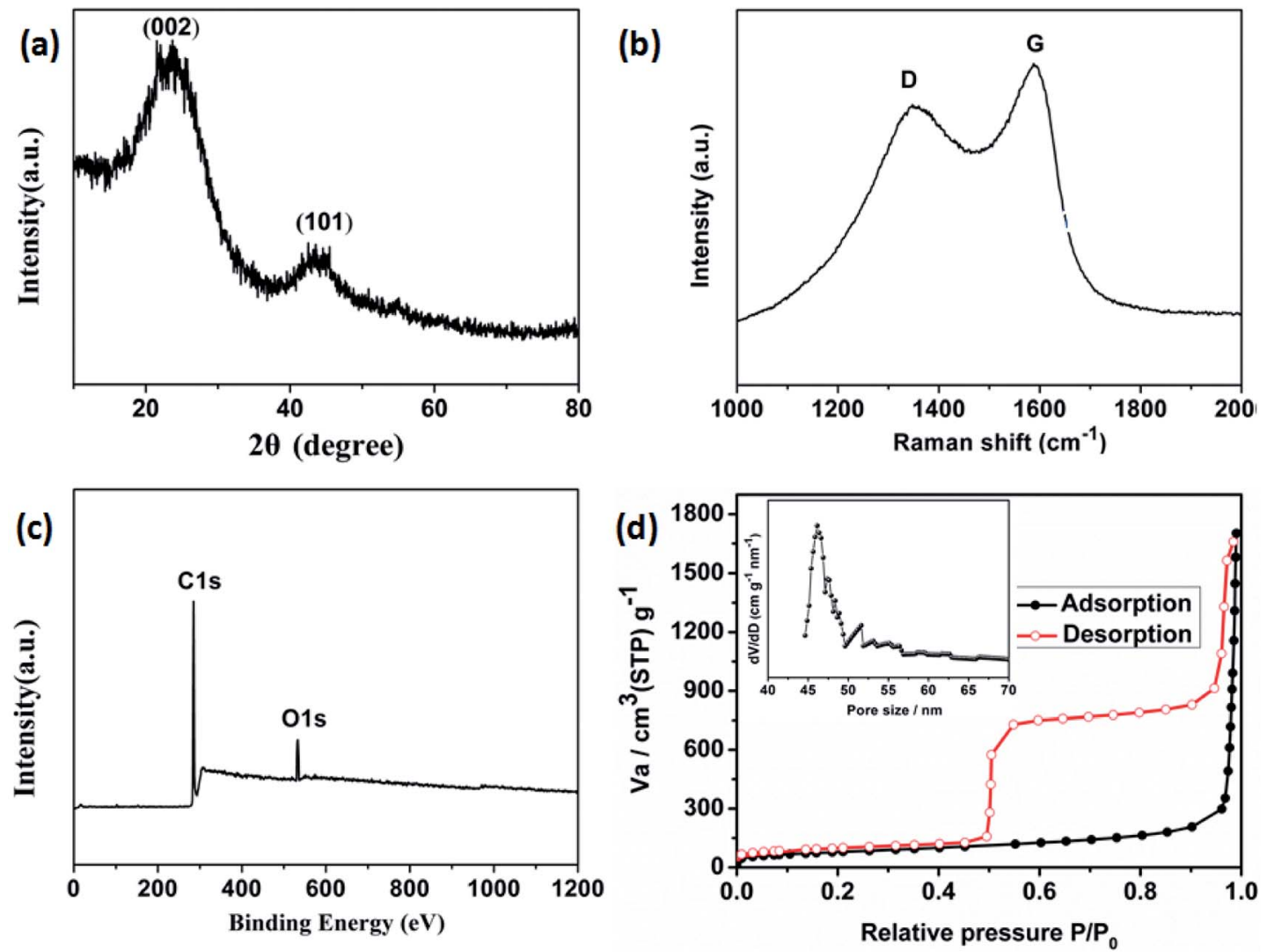

Fig. 4 The obtained porous carbon. (a) XRD pattern, (b) Raman spectrum, (c) XPS spectrum, and (d) nitrogen adsorption-desorption isotherms (inset) pore-size distribution calculated by the $\mathrm{BJH}$ model. 

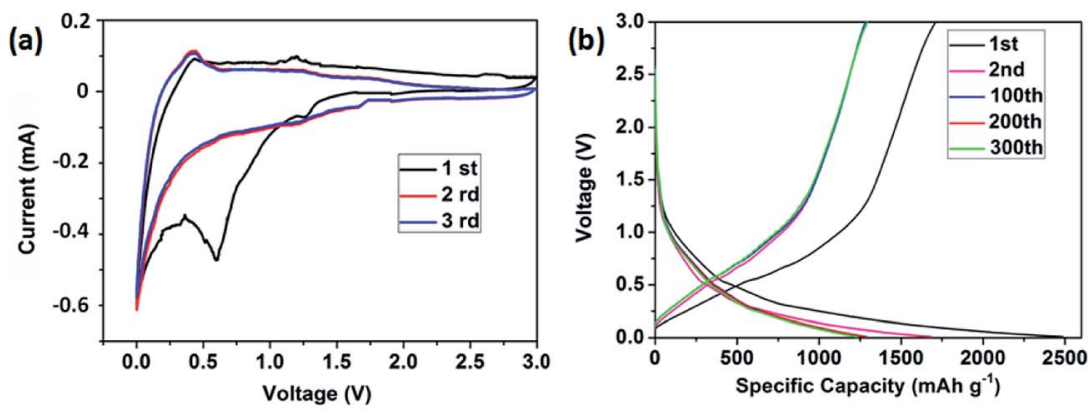

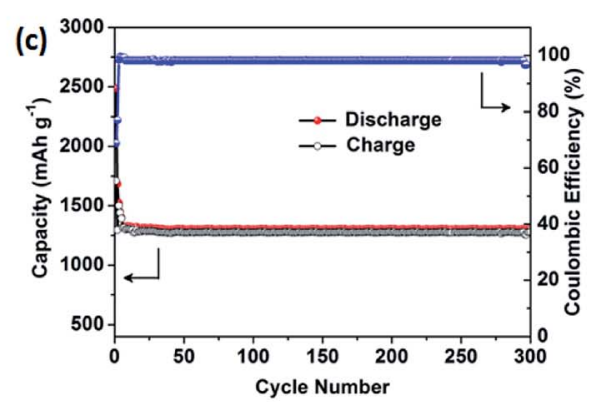

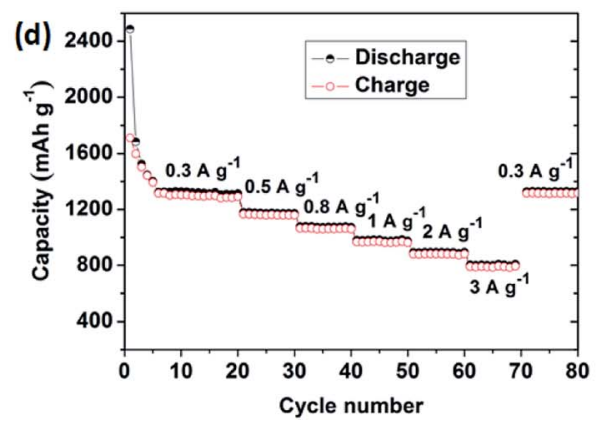

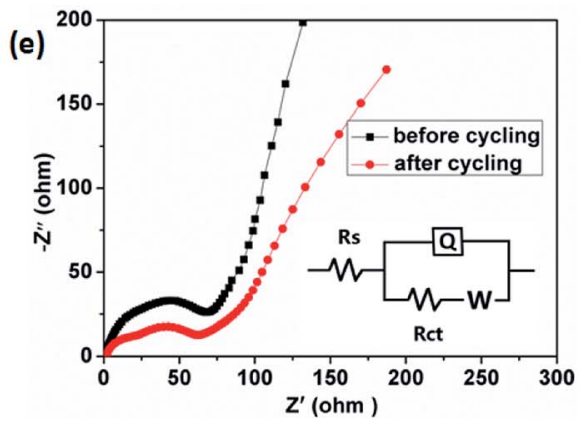

Fig. 5 Electrochemical properties of the porous carbon electrode. (a) Cyclic voltammetry measurements during the first three cycles. The voltage range was from 0.01 to $3.0 \mathrm{~V}$ at a scan rate of $0.1 \mathrm{mV} \mathrm{s}^{-1}$. (b) Discharge-charge curves. The cell was tested for 300 cycles between 0.01 and $3.0 \mathrm{~V}$ under a current density of $300 \mathrm{~mA} \mathrm{~g}^{-1}$. (c) Cycle-life performance and coulombic efficiency at a current rate of $300 \mathrm{~mA} \mathrm{~g}{ }^{-1}$ over 300 cycles. (d) Rate capability test at various current densities $\left(300-3000 \mathrm{~mA} \mathrm{~g}^{-1}\right.$ ). (e) Nyquist plots before and after discharge-charge cycles. The insert is the proposed equivalent circuit.

agrees with the irreversible reduction of electrolyte and the formation of a solid electrolyte interface (SEI) layer. ${ }^{30,31} \mathrm{~A}$ oxidation peak at approximately $1.21 \mathrm{~V}$ is observed during the charge process. In the subsequent two cycles, the cathodic peak disappears and the overlapping curves are found, demonstrating the electrochemical reversibility is gradually built.

Fig. $5 \mathrm{~b}$ shows the charge-discharge voltage profiles of the porous carbon electrode at a constant current density of $300 \mathrm{~mA}$ $\mathrm{g}^{-1}$. The first discharge and charge capacities of the carbon electrode are 2486 and $1683 \mathrm{~mA} \mathrm{~h} \mathrm{~g}^{-1}$, respectively, leading to an initial coulombic efficiency of $68 \%$. The large capacity loss can be attributed to the formation of a SEI film and decomposition of the electrolyte, which are common to most anode materials. ${ }^{32,33}$ Fig. $5 \mathrm{c}$ shows the cycling performance and corresponding coulombic efficiency at a current density of $300 \mathrm{~mA}$ $\mathrm{g}^{-1}$. Obviously, after a few discharge-charge cycles, the electrode exhibits excellent cyclic capacity retention and their coulombic efficiency steadily remains above $99 \%$. At the end of 300 charge-discharge cycles, a reversible capacity of $1285 \mathrm{~mA} \mathrm{~h}$ $\mathrm{g}^{-1}$ can still be retained.

The rate capability of the carbon electrode is evaluated at various current densities from 300 to $3000 \mathrm{~mA} \mathrm{~g}^{-1}$, as presented in Fig. 5 d. As the current density increased from 300 to 500,800 , 1000,2000 , and $3000 \mathrm{~mA} \mathrm{~g}^{-1}$, the capacity decreased slightly from 1285 to $1172,1073,974,886$, and $783 \mathrm{~mA} \mathrm{~h} \mathrm{~g}^{-1}$, respectively. The discharge capacity can still be recovered to almost the same value by using a small density of $300 \mathrm{~mA} \mathrm{~g}^{-1}$ after deep cycling at a high current density of up to $3000 \mathrm{~mA} \mathrm{~g}{ }^{-1}$, indicating excellent rate capability. Such excellent capacity is higher than the theoretical value of commercial graphite $\left(372 \mathrm{~mA} \mathrm{~h} \mathrm{~g}^{-1}\right)$ and is superior to those previously reported carbon hybrid anode materials, such as amorphous carbon nanotubes (965 $\mathrm{mA} \mathrm{h} \mathrm{g}^{-1}$ at $\left.50 \mathrm{~mA} \mathrm{~g}^{-1}\right),{ }^{34}$ carbon nanofibers $\left(400 \mathrm{~mA} \mathrm{~h} \mathrm{~g}^{-1}\right.$ at $\left.200 \mathrm{~mA} \mathrm{~g}^{-1}\right),,^{35} \mathrm{~N}$-doped graphene sheets $\left(896 \mathrm{~mA} \mathrm{~h} \mathrm{~g}^{-1}\right.$ at $\left.50 \mathrm{~mA} \mathrm{~g}^{-1}\right) \cdot{ }^{36}$ Moreover, in comparison with other MOFs-derived porous carbon materials, our carbon electrode shows competitive reversible capacity, such as 3D porous carbon $\left(1015 \mathrm{~mA} \mathrm{~h} \mathrm{~g}^{-1}\right.$ at $\left.100 \mathrm{~mA} \mathrm{~g}^{-1}\right){ }^{26} \mathrm{~N}$-rich carbon nanospheres $\left(1070 \mathrm{~mA} \mathrm{~h} \mathrm{~g}{ }^{-1}\right.$ at $\left.\left.500 \mathrm{~mA} \mathrm{~g}^{-1}\right)\right)^{37}$ ZIF8@chitosan-800N (739 mA h g${ }^{-1}$ at $\left.50 \mathrm{~mA} \mathrm{~g}^{-1}\right),{ }^{38}$ but less than those of other porous carbon materials such as nitrogen-doped porous carbon $\left(2132 \mathrm{~mA} \mathrm{~h} \mathrm{~g}^{-1}\right.$ at $\left.100 \mathrm{~mA} \mathrm{~g}^{-1}\right),{ }^{39}$ multifractal porous carbon $\left(2016 \mathrm{~mA} \mathrm{~h} \mathrm{~g}^{-1} \text { at } 74 \mathrm{~mA} \mathrm{~g}^{-1}\right)^{40}$

To get further insight into lithium-storage properties, the electrochemical impedance spectra (EIS) of the obtained carbon material were investigated before and after 300th charge/ discharge cycles (Fig. 5e). The two Nyquist plots exhibit similar curves consisting of a highfrequency semicircle, a medium-frequency semicircle and a low-frequency straight line, corresponding to the SEI resistance, charge-transfer resistance, and the Warburg diffusion resistance in the solid electrode materials, respectively. ${ }^{41-43}$ The depressed semicircle slightly decreases, indicating that the carbon architectures appeared to reach a stabilized state and lead to the facile charge transfer at the electrode/electrolyte interface after cycling.

\section{Conclusions}

In summary, a 2D $(3,6)$-connected MOF with kgd topology was obtained by application of a tritrophic ligand to assemble with $\mathrm{Cd}(\mathrm{II})$ ions. Meso- and macro-porous carbon material was 
successfully prepared through one-step calcination of the asprepared MOF as template. The resultant carbon electrode exhibited high reversible specific capacity $\left(1285 \mathrm{~mA} \mathrm{~h} \mathrm{~g}^{-1}\right.$ at 0.3 $\mathrm{A}^{-1}$ ) together with superior cyclic stability and good rate capacity. The improved lithium storage is supposed to benefit from the large accessible specific area and unique porous structures.

\section{Acknowledgements}

We gratefully acknowledge the financial support from the National Natural Science Foundation of China (Grant No. 21401059 and 21471061), Science and Technology Planning Project of Guangdong Province, China (2017A010104015 and 2015B010135009), and the Innovation Project of Graduate School of South China Normal University.

\section{Notes and references}

1 W. Xia, A. Mahmood, R. Zou and Q. Xu, Energy Environ. Sci., 2015, 8, 1837-1866.

2 M. Zhang, C. Chen, Q. Wang, W. Fu, K. Huang and W. Zhou, J. Mater. Chem. A, 2017, 5, 349-354.

3 M. I. Nandasiri, S. R. Jambovane, B. P. McGrail, H. T. Schaef and S. K. Nune, Coord. Chem. Rev., 2016, 311, 38-52.

4 Y. Dou, J. Zhou, F. Yang, M.-J. Zhao, Z. Nie and J.-R. Li, J. Mater. Chem. A, 2016, 4, 12526-12534.

5 Q. Xia, Y. Liu, Z. Li, W. Gong and Y. Cui, Chem. Commun., 2016, 52, 13167-13170.

6 N. L. Torad, Y. Li, S. Ishihara, K. Ariga, Y. Kamachi, H.-Y. Lian, H. Hamoudi, Y. Sakka, W. Chaikittisilp, K. C. W. Wu and Y. Yamauchi, Chem. Lett., 2014, 43, 717-719.

7 L. Guang and T. H. Joseph, J. Am. Chem. Soc., 2010, 132, 7832-7833.

8 H. Li, M. Liang, W. Sun and Y. Wang, Adv. Funct. Mater., 2016, 26, 1098-1103.

9 G. Huang, F. F. Zhang, X. C. Du, Y. L. Qin, D. M. Yin and L. M. Wang, ACS Nano, 2015, 9, 1592-1599.

10 D. Kundu, E. Talaie, V. Duffort and L. F. Nazar, Angew. Chem., Int. Ed., 2015, 54, 3431-3448.

11 W. Chaikittisilp, M. Hu, H. Wang, H. S. Huang, T. Fujita, K. C. Wu, L. C. Chen, Y. Yamauchi and K. Ariga, Chem. Commun., 2012, 48, 7259-7261.

12 A. J. Amali, J. K. Sun and Q. Xu, Chem. Commun., 2014, 50, 1519-1522.

13 N. L. Torad, R. R. Salunkhe, Y. Li, H. Hamoudi, M. Imura, Y. Sakka, C. C. Hu and Y. Yamauchi, Chem.-Eur. J., 2014, 20, 7895-7900.

14 Y. Liu, X. Xu, M. Wang, T. Lu, Z. Sun and L. Pan, Chem. Commun., 2015, 51, 12020-12023.

15 A. Li, Y. Tong, B. Cao, H. Song, Z. Li, X. Chen, J. Zhou, G. Chen and H. Luo, Sci. Rep., 2017, 7, 40574-40582.

16 X.-M. Lin, J.-L. Niu, P.-X. Wen, Y. Pang, L. Hu and Y. P. Cai, Cryst. Growth Des., 2016, 16, 4705-4710.

17 L. Hu, X.-M. Lin, J. Lin, R.-Q. Zhang, D.-L. Zhang and Y. P. Cai, CrystEngComm, 2016, 18, 9307-9315.
18 X. M. Lin, T. T. Li, L. F. Chen, L. Zhang and C. Y. Su, Dalton Trans., 2012, 41, 10422-10429.

19 L. Hu, X. M. Lin, J. T. Mo, J. Lin, H. L. Gan, X. L. Yang and Y. P. Cai, Inorg. Chem., 2017, 56, 4289-4295.

20 X. M. Lin, J. L. Niu, J. Lin, L. M. Wei, L. Hu, G. Zhang and Y. P. Cai, Inorg. Chem., 2016, 55, 8244-8247.

21 X. M. Lin, J. L. Niu, D. N. Chen, Y. N. Lu, G. Zhang and Y. P. Cai, CrystEngComm, 2016, 18, 6841-6848.

22 X. M. Lin, T. T. Li, Y. W. Wang, L. Zhang and C. Y. Su, Chem.Asian J., 2012, 7, 2796-2804.

23 CrysAlisCCD Version, 7, 1.171.31, Oxford Diffraction Ltd., 2006.

24 G. M. Sheldrick, Acta Crystallogr., Sect. C: Struct. Chem., 2015, 71, 3-8.

25 A. L. Spek, Acta Crystallogr., Sect. C: Struct. Chem., 2015, 71, 9-18.

26 L. Zuo, S. Chen, J. Wu, L. Wang, H. Hou and Y. Song, RSC Adv., 2014, 4, 61604-61610.

27 X.-M. Lin, J.-L. Niu, J. Lin, L.-M. Wei, L. Hu, G. Zhang and Y.-P. Cai, Inorg. Chem., 2016, 55, 8244-8247.

28 X. Han, W. M. Chen, X. Han, Y. Z. Tan and D. Sun, J. Mater. Chem. A, 2016, 4, 13040-13045.

29 Y. Chen, X. Li, K. Park, J. Song, J. Hong, L. Zhou, Y. W. Mai, H. Huang and J. B. Goodenough, J. Am. Chem. Soc., 2013, 135, 16280-16283.

30 F. Zheng, G. Xia, Y. Yang and Q. Chen, Nanoscale, 2015, 7, 9637-9645.

31 Y. Han, M. L. Zhao, L. Dong, J. M. Feng, Y. J. Wang, D. J. Li and X. F. Li, J. Mater. Chem. A, 2015, 3, 22542-22546.

32 F. C. Zheng, D. Q. Zhu and Q. W. Chen, ACS Appl. Mater. Interfaces, 2014, 6, 9256-9264.

33 W. M. Chen, L. Qie, Y. Shen, Y. M. Sun, L. X. Yuan, X. L. Hu, W. X. Zhang and Y. H. Huang, Nano Energy, 2013, 2, 412-418. 34 Y. Chen, Z. Lu, L. Zhou, Y. W. Mai and H. Huang, Energy Environ. Sci., 2012, 5, 7898-7902.

35 C. Li, X. Yin, L. Chen, Q. Li and T. Wang, J. Phys. Chem. C, 2009, 113, 13438-13442.

36 Z. S. Wu, W. Ren, L. Xu, F. Li and H. M. Cheng, ACS Nano, 2011, 5, 5463-5471.

37 Z. Xie, Z. He, X. Feng, W. Xu, X. Cui, J. Zhang, C. Yan, M. A. Carreon, Z. Liu and Y. Wang, ACS Appl. Mater. Interfaces, 2016, 8, 10324-10333.

38 Y. Han, P. Qi, S. Li, X. Feng, J. Zhou, H. Li, S. Su, X. Li and B. Wang, Chem. Commun., 2014, 50, 8057-8060.

39 F. Zheng, Y. Yang and Q. Chen, Nat. Commun., 2014, 5, 1-10. 40 A. Li, Y. Tong, B. Cao, H. Song, Z. Li, X. Chen, J. Zhou, G. Chen and H. Luo, Sci. Rep., 2017, 7, 40574-40581.

41 R. Wu, X. Qian, F. Yu, H. Liu, K. Zhou, J. Wei and Y. Huang, J. Mater. Chem. A, 2013, 1, 11126-11139.

42 L. Hu and Q. W. Chen, Nanoscale, 2014, 6, 1236-1257.

43 X. Yang, Y. B. Tang, X. Huang, H. T. Xue, W. P. Kang, W. Y. Li, T. W. Ng and C. S. Lee, J. Power Sources, 2015, 284, 109-114. 